Ögut-(Dis)Claiming Identity

\title{
(Dis)Claiming Identity: \\ Christina García's The Agüero Sisters and Julia Alvarez' How the García Girls Lost Their Accents
}

\author{
Özlem Ögüt \\ Bogaziçi University
}

Christine Garcia's The Aguero Sisters and Julia Alvarez's How the Garcia Girls Lost Their Accents are novels that revolve around the conflicts and tensions among the members of the two immigrant families, the Aguero sisters from Cuba and the Garcia sisters from the Dominican Republic, arising mainly from their need to come to terms with their ambiguous identities. This article focuses on the ways in which the Aguero and Garcia sisters through their hybrid identities overcome boundaries and exclusive categories so as to challenge homogenizing, hegemonic systems, and open vistas into new, non-essentialist modes of identity that still can be represented in their specific configurations.

How to make a case for identity without affirming essentializing categories has preoccupied the minds of scholars from a broad range of disciplines such as cultural, ethnic, and gender studies, especially after the upsurge of post-structuralism and theories of hybridity that constitute a strong link between postcolonial, post-modern, and post-feminist conceptions of identity. 


\section{Ethnic Studies Review Volume 26: 1}

Critics from this wide interdisciplinary pool have focused on how to resolve the tension between claims to authenticity or autonomy on the one hand and multiplicity or hybridity on the other as far as various frames of identity are concerned, particularly in the face of the long, multi-faceted history of oppression, colonization, and subordination. Dissolving identity in discourse in an attempt to undermine categories, despite its liberating aspects, has dismayed marginalized groups who had not yet found the opportunity to construct themselves as subjects nor to represent their specificities since they consistently had been defined in relation or in negativity to the subordinating groups. 1 Thus a major concern has been to find ways in which the preestablished hegemonic orders could be challenged without generating new modes of hegemony and hierarchy.

Attempting to overthrow the hegemonic power structure by using its very strategies of naturalizing or fixating identity only reverses the hierarchy. Audre Lorde writes, "For the master's tools will never dismantle the master's house. They may allow us temporarily to beat him at his own game, but they will never enable us to bring about genuine change" (108). By the same token if the postmodernist project to dispense with categories and universalized conceptions of identity in favor of a fluid, hybrid, decentered and de-essentialized identity is understood to have no room for autonomy or authenticity, therefore none for resistance, it may prove equally restrictive. ${ }^{2}$ As Gerry Smith argues, "[T] he dissolution of border is far from unproblematic" and "hybridity is also hegemonically recuperable, easily absorbed by those with an interest in denying the validity of a coherent discourse of resistance" (43).

The dialogue between Néstor García Canclini, Raymundo Mier and Margarita Zires concerning the concept of "hybridity" as it pertains to cultural and national identity throws light on the controversial nature of this term. Canclini detects two different movements in Mier and Zires' interpretations of his notion of hybridity: that the hybrid is something indeterminate and constantly changing and that the hybrid becomes formalized during the process of hybridization. ${ }^{3}$ Canclini underscores that the hybrid is subject to constant de-territorialization and re-territorialization even in contemporary societies where the intensity of 
cultural crossings have led to the collapse of paradigms and the difficulty of grasping meaning. ${ }^{4}$ He claims, "The hybrid is almost never something indeterminate because there are different historical forms of hybridization" (79).

The dialogue between the works of Simon During and Linda Hutcheon concerning the relationship between post-colonialism and post-modernism displays a similar pattern: During underlines the paradox of post-modernity that "refuses to turn the Other into the Same" thus providing a theoretical space for "otherness" which it actually denies but also recognizing that "the Other can never speak for itself as the Other" (125). During's thesis is "that the concept post-modernity has been constructed in terms which more or less intentionally wipe out the possibility of post-colonial identity" (125). He remarks, "[P]ost-colonialism is regarded as the need, in nations or groups which have been victims of imperialism, to achieve an identity uncontaminated by universalist or Eurocentric concepts or images" (125). In her "Circling the Downspout of Empire" Linda Hutcheon complicates During's definition of post-colonialism, noting that "the entire post-colonial project usually posits precisely the impossibility of that identity ever being "uncontaminated'" (135). She contends that both the post-colonial and the post-modern resist any totalizing system or hegemonic force that presumes centrality by "granting value to (what the centre calls) the margin or the Other" and that both post-modernism and post-colonialism undertake a dialogue with history (133).

After modernism's ahistorical rejection of the burden of the past, post-modern art sought self-consciously (and often parodically) to reconstruct its relationship to what came before; similarly, after that imposition of an imperial culture and that truncated indigenous history which colonialism has meant to many nations, post-colonial literatures are also negotiating (often parodically) the one tyrannical weight of colonial history in conjunction with the revalued local past (131).

Hutcheon proposes irony and parody as powerful subversive tools which, in their capacity to represent doubled identities, can challenge the paradoxical move by colonialism to enforce cultural sameness while at the same time producing differentiations and discriminations (133). 


\section{Ethnic Studies Review Volume 26: 1}

The tension between authenticity and multiplicity with reference to identity also constitutes the focus of gender and feminist studies as reflected in the works of Teresa De Lauretis and Judith Butler. ${ }^{5}$ Linda Alcoff writes that in Alice Doesn't: Feminism, Semiotics, Cinema Teresa de Lauretis spells out the dilemma between a post-structuralist genderless subject that erases sexual difference from subjectivity and a cultural feminist essentialized subject" (109). Alcoff underlines that De Lauretis develops the beginnings of a new conception of dynamic, "positional" subjectivity that involves "the continuous engagement of a self or subject in social reality" and a "political, theoretical selfanalyzing, reflexive practice". As such the subject can "alter discourse and be altered and reconstructed by it" (109-110). Alcoff highlights the importance of De Lauretis' work as follows:

Gender is not a point to start from in the sense of being a given thing but is, instead, a posit or construct, formalizable in a nonarbitrary way through a matrix of habits, practices, discourses. Further, it is an interpretation of our history within a particular discursive constellation, a history in which we are both subjects of and subjected to social construction (114).

Judith Butler's view of gender identity as "performing"' within historical/cultural discourses so as to produce agency to subvert them constitutes another significant challenge to making essential and universal conceptions of gender, which, however, does not disregard or exclude gender specificity nor the possibility of resistance. As Robert M. Strozier points out, Butler holds that discourse is prior to and constitutes subjective identity but that discursively mandated performance produces agency from within itself through the periodic repetition of the received categories, the supposedly "original" or "natural" roles:

[G] ender as performance over time necessitates repetition; and repetition inevitably involves failure or slippage, which in turn creates a self-reflexive stance; the consequence is produced agency-by the same discursive regulations which produce gendered subjectivity (Strozier 88).

Strozier further remarks that according to Butler, "Agency and (the possibility of) resistance are not assumed as properties 


\section{Ögut-(Dis)Claiming Identity}

of the pregiven subject; the subject constructed by discoursepostdiscursive-has produced in it the capacity/or positionality for resistance to the constituting discourse" (83). He describes Butler's argument in her Gender Trouble as "based on the belief that any a priori conception of the ' $w e^{\prime}$ ' as essentializing notions of 'female' and 'woman' work to the detriment of 'feminist political theorizing'; they are an employment of 'the imperialist strategies' that feminism must eschew, and most important they operate as a constraint on 'the very subject' feminist theory hopes to represent and liberate" (82). 6

The two novels to be explored here, Christina García's The Agüero Sisters and Julia Alvarez' How the García Girls Lost Their Accents, are concerned with the issues of origins, change, resistance, and identity construction. They open vistas to new conceptions of subjectivity that respond to the pressing issue of how to resolve the dichotomy between authenticity and multiplicity, representation and discursion, so as to engender the most liberated and egalitarian forms of identity. The notion of identity that emerges in both novels does not conceive of these above-mentioned categories as mutually exclusive but embraces both, thereby doing justice both to specificity and hybridity. It does not seek to separate but engage "self" and "other" in such a way that their interaction not only transforms both but also accentuates the specificities of each. As eminent examples of immigrant literature, The Agüero Sisters and The García Girls challenge both in form and content the pre-established categories, constantly reinscribing them but never erasing them or prioritizing one over the other.

The four García sisters, Carla, Sandra,Yolanda, and Sofía, who are in their early thirties and late twenties, and the two Agüero sisters, Reina and Constancia, who are in their late forties and early fifties respectively have something very significant in common. The characters in both novels experience an almost traumatic separation and displacement, which expose them to completely different life styles than the ones they were used to and trigger a process of self-reflection along with their ongoing attempts to come to terms with their past and to accommodate it to the present.

Both the García and the Agüero sisters come from well-edu- 


\section{Ethnic Studies Review Volume 26: 1}

cated and wealthy Hispanic families, the descendants of the Conquistadors, who have continued the tradition of colonizers after the independence of their countries, the Dominican Republic and Cuba respectively. The García girls, as daughters of the prominent de la Torre family, live snugly and carefree in their mansion surrounded by large areas of land adjacent to those of their relatives, all of whom keep Haitian servants and chauffeurs. Father García de la Torre, a doctor, conducts research in collaboration with American doctors who later make arrangements for him and his family to flee the country and move to the United States due to the increasing threats from the dictator Trujillo. This marks a dramatic change in the lives of the Garcia sisters who now struggle to cope with the tension between their Dominican and American identities, the past and the present, and the conflicting impulses to conform and rebel. The novel may initially seem to delineate the girls' successive experiences of foreignness, "Americanization" and "Americanness" that parallel their painful separation from, their rejection of, and finally estrangement from their Caribbean origin, but in fact the gradual expansion of their cross-cultural experiences will increase the deeper-lying urge on the part of the girls to embrace and incorporate their past into their current identity. The fact that Yolanda, the third sister who also appears as the protagonist of the novel, decides to return to the island with the intention to stay longer, perhaps even for good this time, by itself indicates that the immigrant experience of the García girls cannot be considered in linear or exclusive terms.

Ignacio Agüero, the father of the Agüero sisters, is a wellknown naturalist coming from a family of classical musicians and intellectuals. He takes frequent excursions to forests and swamps to explore rare species with his wife and colleague, Blanca. They lament the imminent extinction of various species as well as their already extinct ancestors due to the growing ecological imbalance in Cuba; therefore they preserve samples of rare species in the spacious Agüero household after shooting and stuffing them. When their daughter, Constancia, is five months old Blanca disappears for months and when she comes back she is pregnant by a black man, which is not explicitly stated in the novel but suggested by references to Reina's darker skin and her 
encounter with a black man by her mother's grave years later, who, as she hears from people there, visits Blanca's grave every day, only to disappear after that encounter. When Reina is born and receives all the attention from her mother, Constancia becomes frustrated and attempts to hurt the baby, whereupon her parents send her to her uncle's ranch where she lives until she emigrates to the US with her husband. The Agüero girls lose their parents when they are still very young. Ignacio shoots Blanca during an excursion to the Zapata Swamp, and "starts telling his lies" as he confesses in his letter to the girls who do not see it until the end of the novel, and he commits suicide two years after the event. Reina is devastated when her mother dies. She never believes his father's explanation of her death. Constancia, on the contrary, remains rather cold and indifferent. Reina refuses to leave the country before and after the Cuban Revolution despite all the hardships that it brings with it and insists on spending the rest of her life in the former Agüero household, in fact, in one of its rooms piled up with her parents' books and relics, since the house accommodates several other families after the Revolution. The two sisters remain separated for over three decades other than their occasional correspondence until Reina, after many years of unwavering dedication to her past, the study of her father's work, her endless rummaging among his books, papers, notes, stuffed bats and animal skins, leaves Cuba to visit her sister in Miami where Consancia tells her that Reina was not Papi's daughter, a secret that she intuitively expected to unravel. For the first time after many years of insomnia Reina can sleep uninterruptedly through the night. Constancia herself returns to Cuba to bury her husband, Herberto, who went there to participate in a counter-revolutionary movement and to uncover the secrets of her family as they would be revealed in her father's letter and some items he had left with her uncle shortly before he died. For the first time Constancia finds solace in the Cuban landscape "where every origin shows. For the first time in her life, she's grateful it's a part of her past" (296).

Before going into an in-depth discussion of the García and Agüero sisters' unbroken, sometimes anxiety-laden, and sometimes reassuring and fulfilling relation to the past, and how it fuels their hybrid identity as well as their potential for resistance 


\section{Ethnic Studies Review Volume 26: 1}

in line with the theories described above, it is important to emphasize the way in which the narrative structure of both novels reflects the intimate and inextricable bond between the past and the present. The themes of exile and return, acceptance and resistance, and constant de-territorialization and re-territorialization of identity also find expression in the non-linear and polyphonic structure of both novels. The narrative in both novels involves a dialogic link between the past and the present, and the polyphony consists in the repetition of the narration of certain experiences from different perspectives, with varying emphases and nuances so as to render them ambivalent and call into question their original form in the history of numerous discourses.

The García Girls consists of three sections in reverse chronology, the first (1989-1972) including episodes from the girls' adult life in the United States, the second (1970-1960) covering their adolescence marked by a rather difficult process of their assimilation to American culture, and the third (1960-1956) relating their childhood memories in the Dominican Republic beginning with the time shortly before their immigration. Only the chapters in the third section that comprise their childhood years in the Dominican Republic are told in the first person indicating that the girls' identities have become so hybrid after their encounter and interaction with the foreign culture that the use of the first person remains exclusive in the face of the plurality of their selves. Even the fact that Yolanda considers returning permanently to the Dominican Republic almost thirty years after their immigration at the beginning of the novel, which is at the same time the end of the story, does not shift the narrative to the first person since she has been transformed irrevocably and since she will keep changing in her new interactions with the people on the island who in turn will undergo changes in their interactions with her. The use of the first person in the last section of the book is also ironic because it is particularly the events in the last section which the girls cannot remember with precision because they were too young then; therefore their accounts of the past are partly inventions. So is their first person subjectivity. There is only one chapter in the novel that is told by the Haitian maid, Chucha , who has served the de la Torre family for over three decades and 


\section{Ögut-(Dis)Claiming Identity}

who can well imagine the way the girls will feel when they leave the island and how they will react to it. Chucha cannot help but associate the family's exile from their home with her own from Haiti and predicts, "They will be haunted by what they do and don't remember. But they have spirit in them. They will invent what they need to survive" (223). Chucha, "Haitian blue-black, not Dominican café-con-leche black" as Sofía describes her, whose family and relatives were executed by Trujillo's soldiers and who experienced severe racial discrimination in the Dominican Republic before she was employed as a maid by the de la Torre family, cannot help but fear for the girls now:

They are gone, left in cars that came for them, driven by pale Americans in white uniforms with gold braids on their soldiers and on their caps. Too pale to be living. The color of zombies, a nation of zombies. I worry about them, the girls, Doña Laura, moving among men the color of the living dead (221).

Chucha's emphasis on the skin color of the Americans not only expresses her worry that the girls will experience discrimination in the United States due to their race and ethnicity but also implies that the girls' distinct Dominican identity, their relation to their past, may gradually fade during the course of the assimilation process, whether it be overtly or covertly imposed by the Americans or desired by the girls themselves. Chucha who has always maintained her Haitian traditions and rituals despite her assimilation to the Dominican household and her subject position, also knows deep inside that the girls will never completely break their ties with their past. Indeed the reverse chronology of the novel emerges as an attempt to reconstruct the past although it also problematizes the notion of a recoverable past as well as an original, uncontaminated identity.

The Agüero sisters also are haunted by the past, by what they do and do not remember and what they do and do not want to remember. The major irony in the novel is that the memories that the protagonists would rather forget impress themselves with greater force upon them, and that the "truths" they would like to remember or find out escape them. As in The García Girls, the polyphonic structure of The Agüero Sisters and the abundance of irony emerge as strategies that challenge the traditional forms of 


\section{Ethnic Studies Review Volume 26: 1}

narrative and the closure of meaning. The novel consists of two alternating series of narrative, both abounding in flashbacks: one by an omniscient narrator who relates chapters from the lives of the two sisters and another by Ignacio Agüero, their father, who gives an account of his life, marriage, how he murdered his wife, and his suicidal thoughts. The chapters are preceded by a "Prologue" that describes the day when Ignacio killed his wife, yet reveals nothing about why he did that or whether or not it was an accident. The episodes that contain Ignacio Agüero's narrative are in fact parts of his letter to his daughters, which remain in their uncle's possession for over three decades until Uncle Dámaso decides to write to Constancia about it. As the novel draws to a close Constancia returns to Cuba after thirty years of separation to uncover the secrets of her family as they would be revealed in her father's letter. The novel ends with Ignacio Agüero's account of the incident at the Zapata Swamp, which was described in the "Prologue" yet remains rather ambivalent as to the reasons for his act and is far from unraveling the secrets surrounding the history of the Agüero family: What compelled Blanca to leave home? What was the nature of her relationship with the black man, Reina's real father, who had given Blanca bruises but visited her grave every day for years? Was it love or was it the same urge to know the "other," the "endangered," the "unknown" that was also the stimulus for her excursions into the woods? What was the black man's motive? Was it love? Was it rape? If so, was it revenge on the oppressor or an act on impulse? What was Ignacio's reason for killing Blanca? Was it jealousy? If so, was it because of her adultery or her intuitive relationship with nature, which made her a better scientist than himself? Or did he want to preserve her youth and beauty like the animal samples in his house? What caused Blanca's estrangement from Constancia and Ignacio's closeness to Reina although she was not his daughter? The answers to these questions are irretrievably lost to Reina and Constancia as well as to the reader.

Christina García's The Agüero Sisters and Julia Alvarez' How the García Girls Lost Their Accents not only resist totalizing meanings by blurring the distinction between the past and the present, the beginning and the end, the real and the imagined/invented. They also suggest a new mode of hybrid 


\section{Ögut-(Dis)Claiming Identity}

identity whose authenticity resides in its multiplicity. The characters in both novels attain and display the kind of subjectivity that De Lauretis, Hutcheon, and Butler proposed as multi-faceted and non-essentialized, yet possessing the capacity to resist dominant orders and to represent its specificities. In the two novels, identity emerges as "positional" in the sense De Lauretis uses it, as "performative" and "self-reflexive" in the sense Butler conceives of it, and as "doubled" by parody and irony in Hutcheon's terms. As noted earlier, in order for all this to happen, the characters had to experience one or several displacements and exposure to different cultural, social, and political environments. In their attempts to accommodate themselves to changing situations and new cross-cultural frameworks, they discover and expand their capacity to resist and challenge all totalizing and/or hegemonic systems, including the ones their pre-exile situation involved.

The García girls' earlier immigrant experiences are rather frustrating mainly because they had to leave their relatives and the conveniences of de la Torre household behind. For the first time they find themselves in a subordinate position, submitting to the demands of the foreign culture and the native citizens of the host country who regard them as different, exotic people. The discriminatory attitude of some of their neighbors and schoolmates makes them feel displaced and peculiar and therefore nostalgic about their life back at home.

You can believe we sisters wailed and paled, whining to go home. We didn't feel we had the best the United States had to offer. We had only second-hand stuff, rental houses in one redneck Catholic neighborhood after another, clothes at Round Robin.... Cooped up in those little suburban houses, the rules were as strict as for Island girls, but there was no island to make up the difference (107).

However, it does not take long for the girls to develop a taste for the American teenage life:

"Soon, Island was the hair-and-nails crowd, chaperones, and icky boys with all their macho strutting and unbuttoned shirts and hairy chests with gold chains and teensy gold crucifixes" (109). 


\section{Ethnic Studies Review Volume 26: 1}

During this period of time when they feel "more than adjusted" they became reluctant to spend the whole summer on the island although they "wouldn't mind a couple of weeks." They revolt against their parents' overprotective attitude and obsessive attempts to maintain Dominican family values and traditions, which contradict their simultaneous encouragement for assimilation and Americanization on the premise that it's "a free country."

The idea of America as "a free country" is constantly parodied and emptied of its content; it is shown to be a myth perpetuated by the hegemony of both the parents and the empire. One of the most striking instances of the repeated suggestion of the "the free country" concerns Yolanda's Teacher's Day address that she is asked to deliver at the school assembly. The quotes in her first draft from Whitman's poetry, "I celebrate myself and sing myself." and "He most honors my style who learns under it to destroy the teacher," infuriate her father whom she in turn accuses of being a dictator although he himself fought against and fled from dictatorship and men in uniforms. Yolanda has to revise the draft of her Teacher's Day address. The audience applauds enthusiastically because the text stands out as a true homage to American patriotism. Yolanda's experience is an instance of "the interrogation of the narrative of nation by the strategy of repetition and rehearsal through which the narrative is performed" and displays how the term "free" in the narrative of "the free country" is "repeated by the multiple and contending voices of the people with such differing inflection" in the narrative of migration and settlement (Stoneham 82). Geraldine Stoneham stresses Homi Bhabha's notion of the Nation as "in a state of cultural liminality-of perpetual rehearsal-always radically alienated within It/Self" (82) referring to "a split between what Bhabha calls the authoritative pedagogical construction of the people as 'historical object' (the People as One)" and "the people as 'subjects' of a performative function, that is, 'the living principle of the people as that continual process by which the national life is redeemed and signified as a repeating and reproductive process' $^{\prime \prime}(82) .{ }^{7}$ Having to reproduce and perform the conventional narrative of freedom without the freedom to modify it, Yolanda learns that the rhetoric and truth of freedom, the idea 


\section{Ögut-(Dis)Claiming Identity}

and the act are two different things, which testifies to Bhabha's notion of the nation as alienated within itself.

Another episode from Yolanda's life, in which the idea of "the free country" is parodied revolves around her relationship with her arrogant boyfriend, Rudy, who tries to convince Yolanda to sleep with him by reminding her that she lives in a free country and should rid herself of Dominican taboos. In fact all that Yolanda needs to be persuaded is deep feeling and sensitivity, which Rudy seems to lack. She thinks that Rudy is incapable of understanding her notion of love and her expectations from a relationship. Rudy's directness about sex, or "lovemaking" as Yolanda would prefer to call it, irritates her: "But the guy had no sense of connotation in bed. His vocabulary turned me off even as I was beginning to acknowledge my body's pleasure" (96). She is equally annoyed by the attitude of Rudy's parents who are always conscious of her foreignness and treat her "like a geography lesson for their son" (98). After her painful break-up with Rudy she says, "I saw what a cold, lonely life awaited me in this country. I would never find someone who would understand my peculiar mix of Catholicism and agnosticism, Hispanic and American styles" (99).

Yolanda's marriage with her "monolingual husband" Joe is also far from fulfilling and ends rather dramatically. She writes him a note, "I'm going to my folks till my head-slash-heart clear," revises it, "I'm needing some space, some time, until my headslash-heart-slash-soul-" (78). She does not finish her sentence because she does not want to divide herself even more. Soon after this incident she becomes institutionalized, and there she receives the doctor's confirmation that "we constantly have to redefine the things that are important to us. It's okay not to know" (82). Owing to her "positional" identity Yolanda becomes an acclaimed "poet-slash-writer".

The fact that Yolanda achieves such great success as a poet in a language that is not her own indicates that she can transform the dominant culture. She has always been aware of the discriminatory attitude behind the extremely caring and condescending behavior of her teachers towards her who are in fact overly conscious of her difference/otherness and try to assist her in her assimilation process. The disconcerting effect on Yolanda 


\section{Ethnic Studies Review Volume 26: 1}

of this kind of attitude displays parallels with Wolfgang Welsch's discussion of the concept of multiculturality, which presumes "the existence of clearly distinguished, in themselves homogenous cultures" that must live together within one society. He holds that multiculturalism affirms the traditional conception of cultures as autonomous spheres, accepts and even furthers social barriers. "The concept seeks opportunities for tolerance and understanding, and for avoidance or handling of conflict" (196197). At first Yolanda refrains from speaking in public because of her foreign accent in high school, but as her stories and compositions receive credit and are read out loud in her English classes she gains self-confidence. Although she initially feels rather self-conscious, like "an intruder upon the sanctuary of English majors,"(89) at college she starts co-authoring poems with the self-assured Rudy and finally establishes herself as an eminent poet/writer. Homi Bhabha's argument that hybridity "displays the necessary deformation and displacement of all sites of discrimination and domination" finds expression in Yolanda's assessment of American culture and language.(8) Yolanda operates within "the hybrid space of cultural difference, an ambivalent encounter between the pedagogic and the performative within the language of nationalism itself. The rehearsal of the narrative of the identity of the US only serves to emphasize the split within the idea of the nation itself" (Stoneham 91). Yolanda's position displays "transculturality" which Wolfgang Welsch defines as "the cross-cultural development [that] will increasingly engender a cultural constitution which is beyond the traditional, supposedly monocultural design of cultures"(206). By overcoming social and cultural barriers and thereby demoting the monolithic conceptions of culture, Yolanda's poetry exemplifies transcultural interaction which Welsch describes as follows:

The concept of transculturality aims for a multi-meshed and inclusive, not separatist and exclusive, understanding of culture. It intends a culture and society whose pragmatic feats exist not in delimination, but in the ability to link and undergo transition. In meeting with other life-forms there are always not only divergences but opportunities to link up, and these can be developed and extended so that a common life-form is fash- 
ioned which includes even reserves which hadn't earlier seemed capable of being linked in (200-201).

The García girls' immigrant experience intensifies their transculturation process to which they have been subject since their birth although they do not take a self-reflective stand toward their hybrid identity when they are younger. They are descendants of European colonizers, Spanish conquistadors; Sandra, the third daughter, does not even look Hispanic with her "fine looks, blue eyes, peaches and ice cream skin" which she inherited from her Swedish great-grandmother. However they have been exposed to the indigenous culture of the island ever since they were born, owing to their interaction with the domestics who were natives of the island. The three eldest sisters, Carla, Yolanda, and Sandra, are alarmed by the way their youngest sister, Sofía (Fifi), looks after she spends a year on the island, but they do not realize that their description of Fifi's looks as being typical of a different category entails the deconstruction and hybridization of that very category itself:

Fifi--who used to wear her hair in her trademark, two Indian braids that she pinned up in the heat like an Austrian milkmaid. Fifi--who always made a point of not wearing makeup or fixing herself up. Now she looks like the after person in one of those before-after make-overs in magazines....She's turned into a S.A.P....

a Spanish-American princess (117-118).

Carla, the eldest sister, a psychoanalyst who analyzes people who suffer from maladaptation or lack of self-confidence, interprets Sofía's decision to stay on the island as "a borderline schizoid response to traumatic cultural displacement" (117). However where does she place displacement, in the US or the Dominican Republic: in Sofía's case, "the Spanish-American princess who used to wear her hair like an Austrian milkmaid"? The girls' assessment of their youngest sister's situation displays the absurdity of such generalizations, which, as is the case here, are bound to refute themselves.

The three sisters also are upset by Sofía's relationship with their Dominican cousin, Manuel Gustavo, whom they see as the embodiment of Dominican machismo and launch a "revolution" against his "tyranny." Sofía's relationship with Manuel reveals a 


\section{Ethnic Studies Review Volume 26: 1}

very significant aspect of Alvarez' novel: the deconstruction of male identity by the demonstration of the ways in which men are themselves oppressed by the patriarchal system and therefore resort to various forms of transgressions in collaboration with women who suffer from the same restrictions. This becomes evident in the case of Mundin, another cousin, who, despite the role of the chaperone assigned to him by the family, participates in the little escapades of the girls and creates occasions for Sofía and Manuel to enjoy some private time. The girls comment on Mundin's situation as follows: "For just as we, his American cousins, are threatened with island confinement, military school is what's in store for Mundin should he step out of line" (129). Both girls and boys get around regulations and restrictions with each other's help. When Mundin starts enumerating the taboos they can break Carla, Yolanda and Sandra, who call themselves "feminists" cheer in excitement. The three sisters' feminism displays close affinities with Gayatri Spivak's approach to feminism. Spivak stresses the necessity of resistance that consists in deconstructing the hegemonic system, but without affirming the supremacy of another category that is sought to replace it. She points out that the project of feminism to assert female identity and autonomy may result in the reversal of hierarchy rather than its dismissal and emerge as another form of institution:

As in all instituting. . . the subject of feminism is produced by the performative of a declaration of independence, which must state itself as already given, in a constative statement of women's identity and/or solidarity, natural, historical, social, psychological. When such solidarity is in the triumphalist mode, it must want 'to celebrate the female rather than deconstruct the male.' But what female is the subject of such a celebration, such a declaration of independence? If it entails an unacknowledged complicity with the very modes we refuse to deconstruct, a persistent critique may be in order (112-113).

The three girls' deconstruction of the patriarchal order without substituting it with another hegemonic system finds its most striking example in the way they subvert the chaperoning tradition in Dominican society and use it to separate Fifi from their 


\section{Ögut-(Dis)Claiming Identity}

cousin. The girls, their cousin Mundin, and his sister, Lucinda, chaperon Fifi and Manuel only to allow them some private time as opposed to what their parents intended; all of the girls in the group find an excuse to send Mundin home. He feels obliged to do that due to the requirements of male courtesy but is also reluctant to go because he is not supposed to leave the girls alone. When they all go back home together without Fifi and Manuel it raises havoc in the family which results in the couple's separation, thus the fulfillment of the three girls' purpose. After Sofía is pulled out of her consuming relationship with Manuel by her sisters' cunning plans, she takes to traveling and marries a young German whom she met in Peru. Thus Fifi's transculturation continues.

As the Garcia girls grow out of their teenage years and become more and more exposed to cultural diversity they start problematizing generalizations, steretypes, and uniformity. Carla describes American boys:

the blond, snotty-nosed, freckled-faced boys who looked bland and unknowable, whose faces betrayed no sign of human warmth and whose pale bodies did not seem real but were like costumes they were wearing [and who will join] the vast indistinguishable group of American grownups" (156).

At the same time they reconcile with their ambiguous identities. Rather than trying to belong to either side of the threshold they cherish their existence on the boundaries, their embodiment of non-exclusive opposition, which in fact constitutes their freedom. As illustrated in the case of Yolanda, they transform society and become transformed at the same time. Yolanda's return to the Dominican Republic years later indicates that she is conscious of the power of her hybrid identity that can challenge any hegemonic system anywhere, be it at home, in America, or any other place.

Constancia's return to Cuba after three decades of separation and Reina's decision to leave Cuba for the first time in The Agüero Sisters can be explained similarly. Not much is revealed to the reader regarding Constancia's early years of her immigrant experience in the United States as in the case of the García girls. Her story starts with her last few months in New York City where 


\section{Ethnic Studies Review Volume 26: 1}

she and her husband lived for nearly three decades and established themselves as successful business people, Constancia selling her cosmetics in the major department stores of the city and Herberto selling cigars to her prominent customers in his store. After Herberto's retirement they move to Miami where Constancia's business prospers immensely due to the increasing demand from her customers from all over the country. Throughout the story Constancia appears as the successful, wellintegrated Cuban-American woman who, however, is tormented by her childhood memories, particularly her abandonment by her mother whom she tries to erase from her mind.

Constancia's vain attempts to forget the memories of her past constitutes the major irony of the novel since those memories haunt her with ever increasing intensity. Whenever she looks at the mirror she is greatly disturbed by her resemblance to her mother. Even the plastic surgery she undergoes enhances the resemblance between her and Mama's face although she would rather see the opposite. On the other hand Constancia names all her perfumes and beauty products after Cuba, using ingredients that are native to Cuba. Furthermore she labels the cans and bottles which contain her products with Mama's picture. Her cosmetic business thrives on her ability to combine science and nature that involves both intuition and precise research, all of which were characteristic of her mother. She mixes, produces, and sells potions, emollients, and creams to protect the human body from the effects of old age, to renew youth and life just as her mother tried to preserve species. Ironically enough there is a very thin line between preserving youth and preserving the past from which she is trying to escape. Constancia's inner peace is restored after her acceptance of the fact that she both was and wasn't Mami's girl just as Reina feels relief after she hears that she both was and wasn't Papi's girl. In fact Reina has always cherished complexity.

What she enjoys most is the freedom from a finality of vision, of a definitive version of life's meaning. After all, it seemed futile to chase what was forever elusive, when reality remained so largely unexplored (12).

The complexity of history and reality also marks identity. In Cuba Constancia realizes "how close we are to forgetting every- 
thing, how close we are to not existing at all" (288). The only way to preserve life consists in embracing the past and integrating it into the present. As a matter of fact, Constancia has always experienced the enriching effects of the past, but it is only toward the end of the novel, as her resemblance to her mother becomes more obvious and her sister who now learns English and enjoys her new relationships with men from different nationalities becomes part of her life again, that her self-reflective process begins. Her business has flourished due to her successful integration of Cuban and American identities. Her greatest mental support has always been her Santero Oscar Pinango, and she has taken inspiration from the radio program La Hora de los Milagros. This is how she manages to compete with American businesses in an American way. She launches big advertising campaigns for her products and promotes them in major department stores. Her products constitute a link between two different cultures, fostering cultural diversity in the sense Wolfgang Welsch uses it:

[Diversity], as traditionally provided in the form of single cultures, does indeed increasingly disappear. Instead, however, a new type of diversity takes shape: the diversity of different cultures and life-forms, each arising from transcultural permeations (203).

Welsch points to the interconnectedness and entanglement of cultures with each other and the emerging hybrid identities:

Wherever an individual is cast by differing cultural interests, the linking of such transcultural components with one another becomes a specific task in identityforming. Work on one's identity is becoming more and more work on the integration of components of different cultural origin. And only the ability to cross over transculturally will guarantee us identity and competence in the long run (199).

The past and the present can only be appreciated and enjoyed in their interrelation and mutual exchange. Just like the García girls, The Agüero sisters become truly liberated only when they recognize and embrace their hybrid identity.

Christina García's The Agüero Sisters and Julia Alvarez' How the García Girls Lost Their Accents are novels which provide 
valuable insights into a new, non-essentialist conception of ethnic, cultural, and sexual identity, whose authenticity resides in its hybridity and the specific constellations of forces operating on it, be they social, political, cultural or emotional. The characters in the two novels develop their strengths from the very aspects of their identities that lead to their subordination - as women and/or immigrants for example- by various hegemonic systems that are effectual in different cultural environments that they inhabit. They challenge those hierarchical orders by deconstructing them through periodic repetition of their premises, and as such displaying their artificial character thus fostering self-reflexive processes in the members of society with whom they come into contact. This ultimately leads to the conception of identity as multi-faceted, dynamic, inclusive and inexhaustible rather than essential, exclusive and reducible.

\section{NOTES}

1 Discursive identity entails the post-structuralist or deconstructive notion of identity as socially constructed rather than being natural, original and pure. Feminism as a movement that was launched by white European women and evolved from essentialising to de-essentailizing stages are now challenged and complemented by black feminists whose theories I would like to characterize as post-feminist theories here. The discursive notion of identity as posited by the poststructuralist or anti-essentialist line of "Western" feminists, particularly Helene Cixous and Julia Kristeva, themselves of mixed ethnic and cultural heritage, contributed much to the cause of marginalized cultures by dismantling hierarchical gender categories and displaying that they were by no means natural but construed and consolidated by dominant, totalizing discourses. Thus, they undermined universalizing attitudes to identity. The black feminists took the discourse on identity one step further emphasizing the need to recognize the differences among women and to deconstruct male identity to affirm specific identities of women, which have been flattened by totalizing discourses.

2 Linda Alcoff notes, "Applied to the concept of woman, the post-structuralist's view results in what I shall call nominalism: the idea that the category "woman" is a fiction, [a non-identity] and that feminist efforts must be directed toward dismantling this fiction [...] [Women's] resistance will not be at all effective if she continues to use the mechanism of logocentrism to redefine woman: she can be an effective resister only 


\section{Ögut-(Dis)Claiming Identity}

if she drifts and dodges all attempts to capture her [...] To assert an essential gender difference as cultural feminists do is to revoke this oppositional structure. The only way to break out of this structure, and in fact to subvert the structure itself, is to assert total difference, to be that which cannot be pinned down or subjugated within a dichotomous hierarchy. Paradoxically, it is to be what is not. Thus feminists cannot demarcate a definitive category of 'woman' without eliminating all possibility for the defeat of logocentrism and its oppressive power" (105).

3 Raymundo Mier's assessment of Canclini's definition of the hybrid in his Culturas híbridas: Estrategias para entrar I salir de la modernidad is as follows: "a frontier species, a happening, the sudden eruption of a morphology still without a well-established place in the taxonomies. The entrance of the hybrid to the taxonomy necessitates the abandonment of this category in favor of another, less drastic, one, which might be the variant, species, et cetera. The hybrid designates a liminality, a material whose existence exhibits the dual affirmation of a substance and its lack of identity, that which is in the interstices, which profiles itself in a zone of shadow, which escapes, at least in appearance, repetition. The hybrid is the name of the material without identity, of an evanescent condition" (77).

4 The use of and emphasis on the terms 'de-territorialization' and 'reterritorialization' mark my assessment of Canclini's argument. These terms have play a prominent place in various works by Gilles Deleuze and Félix Guattari, such as Kafka: $A$ Minor Literature (Minneapolis: University of Minnesota Press, 1986) and A Thousand Plateaus: Capitalism and Schizophrenia (Minneapolis: University of Minnesota Press, 1987).

5 Judith Butler's Gender Trouble: Feminism and Subversion of Identity (New York and London: Routledge, 1990) and Teresa De Lauretis' Alice Doesn't: Feminism, Semiotics, Cinema (Bloomington: Indiana UP, 1984) will be discussed here via Robert M. Strozier and Linda Alcoff respectively.

6 At the core of Strozier's discussion of Butler vis à vis Foucault lies Butler's efficient employment of Foucault's geneology "in the service of dismantling any claim that might be made for a gender determination which emanates from a natural sex" (81) According to Strozier, the significance of Foucault's genealogy lies in its concern with process and change, and in that it raises "the issue of origins, however displaced it may be" (81). Strozier underlines that this discursive notion posits that culture precedes nature and that "the 'prior' nature is generated by the discourse as its justification" (80)

7 Stoneham draws upon Homi Bhabha's views in his "Signs Taken for 


\section{Ethnic Studies Review Volume 26: 1}

Wanders: Questions of Ambivalence and Authority under a Tree Outside Delhi, May 1817" in 'Race', Writing and Difference. Ed. Henry Louis Gates, Jr. (Chicago: Chicago UP, 1986).

8 Again Stoneham refers to Bhabha's "Signs Taken for Wanders." It is important to note here that there are striking parallels between Yolanda's performance and resistance as a hybrid in Alvarez's novel and the protagonist of Bharati Mukherjee's novel Jasmine as discussed by Geraldine Stoneham in her article. Stoneham describes the novel as follows: Jasmine (1989) is the story of a young Indian woman's survival of and through the process of hybridization, first in postcolonial India and then in the cultural melting pot of the United States. Jasmine undergoes multiple hybrid transformations, signalled by successive changes of name [...] each new identity reflecting her adaptation to a new set of cultural circumstances. Importantly, however, Jasmine's intervention in the life of the metropolis also transforms the people and cultures who come into contact with her" (83).

\section{WORKS CITED}

Alcoff, Linda. 1994. "Cultural Feminism versus Post-Structuralism: The Identity Crisis in Feminist Theory." Culture/Power/History: A Reader in Contemporary Social Theory. Ed. Nicholas B. Dirks, Geoff Eley, and Sherry B. Ortner. Princeton: Princeton U P. 96-122.

Alvarez, Julia. 1991. How the García Girls Lost Their Accents. New York: Penguin.

Canclini, Néstor García. 1993. "The Hybrid: A Conversation with Margarita Zires, Raymundo Mier, and Mabel Piccini" The Postmodernism Debate in Latin America: A Special Issue of Boundary 2. Ed. John Beverley and José Oviedo. Trans. Michael Aronna. 20: 7792.

De Lauretis, Teresa. 1984. Alice Doesn't: Feminism, Semiotics, Cinema. Bloomington: Indiana University Press.

During, Simon. 1995. "Postmodernism or Post-colonialism Today." The Post-Colonial Studies Reader. Ed. Bill Ashcroft, Gareth Griffiths, and Helen Tiffin. New York: Routledge. 125-29.

García, Christina. 1997. The Agüero Sisters. New York: Random House.

Linda Hutcheon. 1995. "Circling the Downspout of Empire." "Postmodernism or Post-colonialism Today." The Post-Colonial Studies Reader. Ed. Bill Ashcroft, Gareth Griffiths, 